\title{
Informed consent in sterilisation services: Evidence from public and private health care institutions in Chennai
}

Raja Lakshmi

Follow this and additional works at: https://knowledgecommons.popcouncil.org/departments_sbsr-rh

Part of the Demography, Population, and Ecology Commons, Family, Life Course, and Society Commons, International Public Health Commons, Maternal and Child Health Commons, and the Women's Health Commons How does access to this work benefit you? Let us know!

\section{Recommended Citation}

Rajalakshmi. 2007. "Informed consent in sterilisation services: Evidence from public and private health care institutions in Chennai," Health and Population Innovation Fellowship Programme Working Paper no. 4. New Delhi: Population Council. 
Informed Consent in Sterilisation Services

EVIDENCE FROM PUBLIC AND PRIVATE HEALTH CARE INSTITUTIONS IN CHENNAI

Rajalakshmi 
This report is the result of a project entitled "Informed Consent in Reproductive Health Services," undertaken as part of the Health and Population Innovation Fellowship (HPIF) awarded to the author in 2004.

The HPIF programme is administered by the Population Council, New Delhi and is a continuation of the MacArthur Foundation's Fund for Leadership Development (FLD) fellowship programme that continued over the period 1995 to 2004. The Council is grateful to the MacArthur Foundation for its support to this programme.

The HPIF programme aims to support mid-career individuals who have innovative ideas, leadership potential, and the capacity to help shape policy and public debate in the field of population, reproductive health and rights in general, with a focus on two priority themes — maternal mortality and morbidity, and the sexual and reproductive health and rights of young people. Since the transfer of the programme to the Population Council through 2006, a total of 17 individuals have been supported under the HPIF programme.

\section{For additional copies of this report, please contact:}

Rajalakshmi

Kuber Bhawan

1, Puliyur First Main Road

Trustpuram, Kodambakkam

Chennai - 600024

Phone: 044-24816767

Email: rajalaksh@gmail.com
Population Council

Zone 5A, Ground Floor

India Habitat Centre, Lodi Road

New Delhi -110003

Phone: 011-24642901/02

Email:info-india@popcouncil.org

Web site: http://www.popcouncil.org/asia/india.html

The Population Council is an international, non-profit, non-governmental organisation that seeks to improve the well-being and reproductive health of current and future generations around the world and to help achieve a humane, equitable and sustainable balance between people and resources. The Council conducts biomedical, social science and public health research, and helps build research capacities in developing countries.

\section{Copyright @ 2007 Rajalakshmi}

About the autbor: Rajalakshmi has a Master of Arts in Social Work from the Tata Institute of Social Sciences, Mumbai and a B.A. in Psychology from the University of Madras. She holds a Diploma in Medical Law and Ethics (NLSIU) and is trained in International Health Research Ethics at the Harvard School of Public Health. She has worked in the area of reproductive health and women's rights since 1998. Her last assignment was with the Centre for Women and Law, National Law School of India, Bangalore, as a Research Associate.

Suggested citation: Rajalakshmi. 2007. "Informed Consent in Sterilisation Services: Evidence from public and private health care institutions in Chennai," Health and Population Innovation Fellowship Programme Working Paper, No. 4. New Delhi: Population Council.

\section{Q Population Council}




\title{
Informed Consent in Sterilisation Services
}

\author{
EVIDENCE FROM PUBLIC \\ AND PRIVATE HEALTH GARE \\ INSTITUTIONS IN GHENNAI
}

Rajalakshmi

Fellow

Health and Population Innovation Fellowship Programme 
Introduction

Deconstructing informed, understood and voluntary consent

Process of consent-taking in the context of contraceptive services

Providing comprehensive information

Ensuring that the information provided has been understood

Findings of previous studies on quality of care and the the processs of informed consent

Study setting and design

Study settting

Design

Profile of the study population 10

Quality of "informed" consent

Provision of information 12

Client satisfaction with quality of information provided 13

Quality of documentation of consent

Quality of "voluntary" consent

Conclusion and recommendations

References

Acknowledgements 


\section{List of tables}

Table 1: Profile of sterilisation clients $(\mathrm{N}=246)$

Table 2: Clients' awareness of specific contraceptive methods prior to sterilisation $(\mathrm{N}=246)$

Table 3: Clients' reports of information given by health care providers prior to sterilisation $(\mathrm{N}=246)$

Table 4: Client satisfaction with infomation provided $(\mathrm{N}=246)$

Table 5: Content of consent forms used in participating facilities $(\mathrm{N}=16)$

Table 6: Documentation of consent and women's recall of the content of the consent form $(\mathrm{N}=246)$

Table 7: Among clients who signed the consent form, women reporting experiences of the consent-taking process $(\mathrm{N}=196)$

Table 8: Clients' perceptions of the value of the consent process $(\mathrm{N}=246)$

Table 9: The consent-taking process: Clients' experiences and perceptions $(\mathrm{N}=246)$ 


\section{Introduction}

In the area of contraceptive services, informed consent is not only a critical measure of quality of care but is also a significant reproductive right (UN, 1994). Informed consent implies that the information provided to the client is comprehensive, that the client has fully understood the information, and that the client freely consents to adopting a particular method. For consent to be valid, it is the duty of the provider to ensure that the given information is understood by the client. As the Declaration of Helsinki notes, "after ensuring that the subject has understood the information, the physician should then obtain the subject's freely given informed consent" (Principle 22, in WMA, 2000). The ethical bases for informed consent lie in the principles of autonomy, respect for individuals, self-determination and telling the truth (Cook, Dickens and Fathalla, 2003).

Evidence of the extent to which consent in contraceptive services in India is truly informed is limited. Evidence is also lacking on the processes, consent experiences, and perceptions of women seeking contraceptive (terminal and non-terminal) methods. ${ }^{1}$ The sparse evidence available from the literature on quality of care in reproductive health services in India suggests that information provided to clients is generally incomplete and superficial (Koenig and Khan, 1999). Likewise, anecdotal evidence from India suggests that informed consent is often misunderstood and perceived as a mere formality, that is, of obtaining a signature on a consent form rather than an on-going process that takes place between the provider and the client. Even where a consent form is signed, it is not clear whether providers have made the effort to ensure that the client has understood the information provided. Indeed, while the nature of the doctor-patient relationship in India remains largely hierarchical and paternalistic, with the inclusion of medical services within the Consumer Protection Act (1986), there is an increasing recognition of the rights of patients and, as a result, the need for reviewing the rights and responsibilities of both the client and the provider.

In this context, the objective of this paper is to explore the experiences of women undergoing a particular form of fertility regulation, namely sterilisation or tubal ligation, in a variety of facilities in Chennai, India. The paper examines specifically the nature of information provided to clients, the consent-taking process, the nature of its documentation and the extent to which clients made an informed choice.

\footnotetext{
${ }^{1}$ Informed consent in contraceptive trials has received much attention; to discuss this issue would bowever, be beyond the scope of this paper.
} 


\section{Deconstructing informed, understood and voluntary consent}

The right to access information and appropriate services and to make decisions without fear of coercion constitute the crucial elements of reproductive rights as reflected in the Plan of Action of the International Conference on Population and Development (UN, 1994). Similarly, the issues of informed, understood and voluntary consent have been highlighted both in the Declaration of Helsinki and in the Report of the US National Bioethics Advisory Commission (National Bioethics Advisory Commission, 2001; WMA, 2000).

\section{Process of consent-taking in the context of contraceptive services}

Informed consent in the context of contraceptive services is not a one-time event but a process that comprises several stages. While the decision to adopt a particular method may involve several actors and factors, the process of informed consent largely depends on client-provider interaction, whether in a community or clinic setting. In the context of female sterilisation, for example, while the idea of sterilisation may be introduced to a client through any one of several sources including the media, friends, family members and providers, the most crucial stage at which information and decisions are consolidated is in the course of client-provider interaction. The process of informed consent starts with the first encounter between a provider and a probable client of sterilisation during antenatal registration, contraceptive counselling or prior to abortion. The information provided can be new to the client, clarification of a doubt or misconception, or advice or recommendation. The client should be at liberty to evaluate this information and consult others; however, the provider remains the main source of information even after an apparent choice is made by the client, and the provider has the responsibility to ensure that the information provided is understood by the client.

Finally, the client signs a document, in the process of which more information could be exchanged. Obtaining a signature of consent on a written, dated form is part of the documentation process; however, it is only an authorisation given by the client for the adoption of the prescribed method and does not in itself constitute the process of informed consent. In fact, it is the duty of the provider to continue to inform the client ever after a decision has been made to enable the client to consolidate or review the decision; indeed, there could be withdrawal of consent even after a signature is obtained (termed "informed dissent"; Cook, Dickens and Fathalla, 2003).

In short, the process of informed consent encompasses providing the client comprehensive information, ensuring that this information has been understood and that the client is competent to make an informed decision, and enabling the client to opt for the service voluntarily and without coercion. Translating these abstract principles into actions implies a central role for the provider in the process of informed consent. 


\section{Providing comprehensive information}

As apparent from the above discussion, in the context of contraceptive services, the twin concepts of consent and choice are inextricably linked and one cannot take place without the other. For example, a client may have already decided to opt for a particular contraceptive method before she enters a clinic (i.e., made a choice); however, to provide informed consent, the client must be given comprehensive information on all available contraceptive methods and assisted to evaluate her choices.

The Ministry of Health and Family Welfare (MOHFW) guidelines specify that, as female sterilisation is an irreversible procedure, the client must be informed about the array of alternative options to sterilisation, including non-terminal methods, and the comparative benefits and risks of each method, so that she can decide whether or not she would like to undergo sterilisation (MOHFW, 1999). Assessing clients' awareness of contraceptive methods prior to acceptance is important as it may determine whether they require information on methods other than the one they are seeking (Ravindran, 1999). Reviewing a client's prior contraceptive experience is also a key step in the process of informed decision making (Kim et al., 1998). For example, providers are ideally expected to inform women about the specific after-effects of sterilisation in relation to the method used prior to sterilisation, such as, heavier or less regular periods for previous oral contraceptive users and lighter periods for intra-uterine device (IUD) users (Chaudhuri, 2004).

Once the decision to undergo sterilisation has been taken, clients should be made aware of the availability of different surgical procedures, details of the procedure to be adopted, contraindications and side-effects, preparation for surgery, immediate post-operative complications, long-term consequences, follow-up care, potential failure rates and danger signals. The MOHFW guidelines also note that clients should be informed that there are complications associated with female sterilisation (MOHFW, 1999). ${ }^{2}$ This information may be communicated orally in the course of client-provider interaction and/or in written form, such as through information sheets and the consent form. Clients should also be made aware of their right to make a free decision, clarify doubts and reverse their decision at any time without fear of repercussion.

In countries such as India, where unmet need for contraception remains disturbingly high, attributed in part to persistent myths and misconceptions pertaining to contraception, providers at the point of service delivery can be the most reliable source for unbiased information. Providers are expected to communicate and interact with clients to ascertain their characteristics, specific needs and requirements, and to accommodate changes in the client's decisions. Providers must avoid introducing bias in the information giving process and acting on the principle that "the doctor knows best".

\footnotetext{
2 According to the MOHFW guidelines, immediate post-operative complications include baematoma and wound sepsis; common intra-operative complications include anaesthesia-related complications, uterine perforation and specific complications in contraindicated women; and delayed complications include menstrual irregularities and pelvic pain. For details, see Chaudhuri, 2004; MOHFW, 1999.
} 


\section{Ensuring that the information provided has been understood}

It is the duty of the provider to ensure that the client has understood the information provided about possible contraceptive options and the method to be adopted. However, given the unequal nature of the client-provider relationship, clients may be inhibited from asking questions about the contraceptive method and process. The provider should use simple terms in the local language, use innovative methods of communication (for example, a model of the uterus), repeat critical information at different stages of the consent process, and finally ensure that the woman has understood the key facts about the method (for example, that female sterilisation is an irreversible method, and that it could involve some risk).

As noted, critical information about the contraceptive method and the procedure to be adopted should be contained in the consent form and the client should be able to recall this information. The consent form for female sterilisation should contain the following information: the type surgery to be undertaken (i.e., whether laparoscopic or transabdominal); the fact that that the surgery is irreversible; that alternative methods to female sterilisation are available (such as for example, male sterilisation and non-terminal methods); that anaesthesia would need to be administered, the type of anaesthesia to be administered and associated risks; that in some cases complications can occur; and that there are chances of method failure and hence post-operative symptoms such as missed periods should immediately be reported.

Ideally, the consent form should be administered at least 24 hours before the intended surgery in order that the woman may peruse its contents. Opportunities must be available to the client to seek clarification of any doubts that may arise. It is the duty of the health care provider (doctor, nurse or health worker) who administers the consent form to ensure that the client has read the form or has had the form read out to her, and has understood the information provided in the form. The provider is also expected to sign a declaration that the form was read by the client or read out to the client in a language she understood. It is mandatory for the provider to declare on the consent form that $\mathrm{s} /$ he has explained alternative contraceptive methods to the client, and the merits and risks of each method, and has given the client an opportunity to clarify her doubts.

The documentation of consent serves two purposes. First, it provides the client a source of information about the procedure and her rights. Second, it provides the client the opportunity to make the final decision about whether or not to undergo a particular procedure. In the case of sterilisation, women should be asked to read and sign a consent form that clearly provides this information and enables them to make a final decision.

Competence is the ability of the client to understand the information provided. The Indian Council of Medical Research (ICMR) guidelines state that there cannot be an exception to obtaining informed consent on the grounds that the client is not competent to understand the meaning or relevance of informed consent (ICMR, 2000). Lack of formal education should not be considered as limiting the ability of a client to provide informed consent: "Widespread illiteracy is not a barrier to comprehension, especially since informed consent is more an interactive process than one that depends on reading" 
(Preziosi et al., 1997). Factors that can limit competence include the administration of consent procedures at times when the client may be highly vulnerable or if the client is under physical or mental stress (as reinforced in the MOHFW guidelines, MOHFW, 1999) - while in labour or in the immediate post-partum period, recovering from delivery, anxious to undergo abortion or while seeking admission for delivery — and providers should refrain from taking any form of consent at these times.

\section{Ensuring voluntary acceptance of the service}

As noted earlier, the process of consent-taking must promote respect for a client's autonomy and right to self-determination based on adequate comprehension of relevant information. Providers must ensure that clients have selected the contraceptive method of their own volition and are satisfied with their choice. In the case of family planning, for example, the choice is not just which method to use but whether or not to use a method (ACOG, 2004). Voluntary consent also implies the absence of coercion or pressure. In many settings in India, where females have limited autonomy, it may be common for family or community members to take health decisions on behalf of women. Nevertheless, the concept of voluntary consent underscores that women themselves should have control over their reproductive health decisions.

In the context of female sterilisation, the duty of the provider is to encourage the client to take an independent decision and to check with the woman in private whether her decision to accept the method is free of compulsion or coercion. At the same time, the provider should be sensitive to the fact that the woman may want to consult her spouse or family members, and should facilitate such consultation. While consultation with a spouse is ethically permissible (and desirable), the requirement for spousal authorisation for sterilisation violates the principle of "respect for persons" (National Bioethics Advisory Commission, 2001). There is some evidence that providers may attach more significance to consent from a woman's husband or a senior family member than the woman herself, thereby violating the woman's right to provide final consent (Duggal and Barge, 2004; Gupte, Bandewar and Pisal, 1999).

The consent form should be signed by the client herself and the signature of any other person should not be mandated. Only in rare cases should signatures be obtained from family members after duly informing the client of its necessity and seeking her approval. The provider must ensure that the client signs the form in her/his presence in order to ensure voluntary acceptance. A copy of the signed consent form should be made available on request to the client, and this fact should be made known to all clients. 


\section{Findings of previous studies on quality of care and the process of informed consent}

As noted earlier, few empirical studies have been conducted globally on the issue of informed consent in the provision of contraceptive services. A qualitative study in Mexico that explored client and provider experiences of informed consent in sterilisation services reports a lack of awareness among women clients of their rights, a gender bias among providers in giving more detailed information to male clients than female clients, and providers' belief in obtaining the signature of the partner as well as that of the client for consent. The study also found that providers rarely perceived informed consent as a client's right but rather simply as a form of legal protection and as a process of informing the client or as an agreement between the provider and the client (Mayfield, Perez and Landry, n.d.). A study in Kenya found that providers do not tailor information to meet a client's contraceptive intentions or contraceptive awareness prior to acceptance, and rarely assisted women in fully assessing alternative methods (Kim, Kols and Mucheke, 1998).

No empirical studies have been conducted in India so far on informed consent with regard to contraceptive services. However, insights gleaned from studies that have focused on quality of care in contraceptive services shed light on such related issues as the nature of information exchanged between a provider and a client, coercive measures in family planning and client satisfaction. The findings from these studies suggest that women have effectively little choice in the method adopted: incidents are reported in which sterilisation is made a precondition for abortion (medical termination of pregnancy [MTP]) or is performed following caesarean section deliveries without consent (Ravindran, 1999; Sabala, Swatija and Meena, 2002; Van Hollen, 2003).

With regard to the provision of information on contraception, several studies across India, including the National Family Health Survey-2 (NFHS-2), have assessed the extent to which women were informed about alternative methods and the potential side-effects of contraceptive methods. Findings vary widely: for example, in a study in rural Uttar Pradesh in 1993-94, only 33-42 percent of ever-married women reported that providers had discussed any method of family planning other than sterilisation; 33 percent were told about vasectomy, 35 percent about IUDs, 36 percent about condoms and 42 percent about pills (Khan, Gupta and Patel, 1999). In a multi-centric study of currently married women in the reproductive age group in four states in India, only 43 percent of women in Karnataka reported that they were informed about spacing methods in addition to sterilisation, followed by 26 percent in both Tamil Nadu and West Bengal respectively; in Bihar only 18 percent reported that they were similarly informed (Roy and Verma, 1999). According to the NFHS-2, while nationally, 19 percent of currently married women who were current users of modern family planning methods were informed about other methods of family planning by a public sector provider and 28 percent by a provider in a private facility, in

$6 \quad$ Rajalakshmi 
Tamil Nadu 7 percent and 22 percent of women respectively were similarly informed (IIPS and ORC Macro, 2000). A recent follow-up study in Tamil Nadu (2002-03) shows that 23 percent of currently married sterilised women or their husbands were informed of alternative contraceptive methods at the time of sterilisation (IIPS and Johns Hopkins University, 2005).

Studies also show that the proportion of women reporting that they were informed about the side-effects of various family planning methods was low. Only 22 percent of evermarried women in rural Uttar Pradesh were informed about both the advantages and disadvantages of sterilisation (Khan, Gupta and Patel, 1999). In the multi-centric study referred to above, 47 percent of currently married women in the reproductive age group in Tamil Nadu were informed about the side-effects of sterilisation, compared to 40 percent in West Bengal, 58 percent in Bihar and 89 percent in Karnataka (Roy and Verma, 1999). According to NHFS-2, among currently married women using modern contraceptive methods, 55 percent of women in Tamil Nadu were informed of the side-effects of sterilisation by a health or family planning worker at the time of accepting sterilisation (compared to $22 \%$ nationally) (IIPS and ORC Macro, 2000). In the follow-up study, the proportion of currently married sterilised women or their husbands who were told about the side-effects of sterilisation was 69 percent in Tamil Nadu (IIPS and Johns Hopkins University, 2005).

A few studies have explored the reasons why providers do not give clients comprehensive information. Providers feel, for example, that they are not required to discuss alternative methods and their side-effects once a client has "voluntarily" chosen sterilisation (Visaria, 2000). Indeed, studies in rural Maharashtra and Kerala show that providers perceived that giving information on the side-effects of methods such as sterilisation would discourage women from accepting the method (Kumar, 2006; Murthy, 1999). Pressure to achieve family planning targets has also been noted as a possible reason for giving clients incomplete/ selective information (Khan, Gupta and Patel, 1999; Verma and Roy, 1999). A study of four Indian states, including Tamil Nadu, reports that providers focused on female sterilisation and IUDs rather than discussing all available contraceptive methods, and chose the method for the client rather than allowing the client to decide as they were under pressure to recruit acceptors (Verma and Roy, 1999). Studies also report that provider attitudes to women's sterilisation-related problems are insensitive, especially in the public sector, and that an increasing number of women may be turning to the private sector for sterilisation services (Sabala, Swatija and Meena, 2002). 


\section{Study setting and design}

\section{Study setting}

Data for this paper are drawn from a study conducted in Chennai, the capital of Tamil Nadu state. Tamil Nadu is one of the more socio-economically developed states in India, characterised by higher levels of female literacy compared to other states (64.4\% compared to the all-India average of $53.7 \%$; Tamil Nadu Government website). Fertility and maternal mortality rates, likewise, are considerably below the national average; for example, in 2001 the mean number of children per woman in Tamil Nadu was 2.9 compared to the all-India average of 3.8 (RGI, 2005). Similarly, the maternal mortality rate for Tamil Nadu was 8.8 in 2001-03 as compared to the all-India average of 27.4 (RGI, 2006).

Tamil Nadu is also one of the states where awareness of family planning methods and use of contraception is high. In 1998-99, knowledge of at least one modern contraceptive method was universal in Tamil Nadu; 52.1 percent of currently married women were using some method of contraception (compared to the national average of $48.0 \%$ ), of whom 88 percent had adopted female sterilisation (IIPS and ORC Macro, 2000). The number of female sterilisations conducted in the state has increased from 370,000 in 1999-2000 to 430,000 in 2003-2004 (Tamil Nadu Government, Directorate of Family Welfare website). The age of women sterilisation acceptors and parity at sterilisation are low: 60 percent of sterilisation acceptors had two or fewer children in 1998-99 (Tamil Nadu Government, Directorate of Family Welfare website); the median age at acceptance was 25 years in 199899 (IIPS and ORC Macro, 2000).

Chennai is well-known for its medical services. The city has 110 corporation (public) health centres, four teaching centres with attached tertiary care centres and approximately 400 private hospitals for a total population (including the suburbs) of nearly 8 million (Sreevidya and Sathiyasekaran, 2003). The ratio of beds in private/public facilities in the city is about 48:52. Government doctors work as consultants in private hospitals or run their own clinics/hospitals (Muraleedharan, 1999).

\section{Design}

This report is based on the findings of a larger study conducted in Chennai that explored experiences and perceptions of informed consent among both clients and providers of female sterilisation services. Data was gathered between December 2004 and December 2005. The study involved both a survey and in-depth interviews, and was conducted in a total of 18 hospitals in Chennai that provided family planning/abortion services. Facilities were opportunistically selected: a total of 22 private and four public hospitals located across the city were surveyed Of these, 16 private and two public hospitals consented to house the study. The profiles of these 18 hospitals vary considerably: for example, the smallest was a 10-bedded facility, and the largest, 1,500. Some were multi-speciality facilities while others were dedicated to gynaecology and obstetrics. 
Researchers visited each hospital on pre-selected days and all eligible respondents attending the facility on that day were invited to participate in the study. Trained female interviewers conducted the interviews; care was taken to fix interviews at convenient times for women.

The survey covered a total of 246 women who had undergone sterilisation at these facilities: 187 clients in public hospitals and 59 in private hospitals. Women undergoing abortion and insertion of IUDs (245 and 221 women respectively) were also interviewed in the larger study but these findings are not covered in this report. The provider component, which is not discussed here, comprised 38 in-depth interviews with providers from the 18 hospitals.

The survey comprised exit interviews with clients in the wards or rooms a few hours prior to discharge. Oral consent was obtained from the respondent after checking if she understood what was explained to her, and after enabling her to seek clarifications from the researcher. For the most part, the interview was conducted in private. Women were assured that the information given by them would not affect their access to current or future services, and would be kept confidential. Efforts were also taken to ensure that participation was voluntary; in all cases the participant's right to withdraw at any time or to skip questions was stressed. Each respondent was given the researcher's visiting card at the end of the interview.

In addition, six in-depth interviews were conducted with consenting survey respondents (three women each from private and public facilities). Fresh consent was sought and interviews conducted in their homes. In-depth interviews sought to better understand the decision-making process leading to sterilisation, role of family members in fertility decisions, choice of health facility, nature of provider-client interaction, and specifically with regard to contraception, experiences of consent giving, and clients' opinion of and attitude to the consent process. Privacy was ensured during the interviews and discussions were tape-recorded.

An Ethical Review Committee consisting of social scientists, researchers, and medical and legal professionals reviewed the entire research process. 


\section{Profile of the study population}

As can be seen from Table 1, the demographic profile of the study population is fairly typical of sterilisation acceptors more generally; for example, age at sterilisation is low - the median age at sterilisation (25) in the study setting is similar to that recorded by the NFHS-2 for Tamil Nadu in 1998-99 (IIPS and ORC Macro, 2000). In comparison with the minimum age of 22 for sterilisation recommended by the MOHFW, almost 10 percent of the women clients were aged 21 or less (MOHFW, 1999). Education levels achieved are considerably lower than the average reported for women in urban Tamil Nadu, but underscore the fact that in India, sterilised women are by and large less educated than other women (see for example, IIPS and ORC Macro, 2000; Murthy, 1999). Mean parity at sterilisation is low: on an average women were sterilised after they had two children. Most women had undergone post-partum tubectomy; only few had undergone interval sterilisation $(89.4 \%$ vs $10.6 \%)$. Most respondents resided in nuclear families.

With regard to the health profile of respondents, about one-third (33.7\%) reported at least one health complaint in the three years preceding the survey (not shown in tabular form). Although there are no absolute contraindications for sterilisation, we note that some 8 percent of clients presenting for sterilisation suffered from hypertension, cardiovascular disease, hyperthyroidism, chronic respiratory problems or sexually transmitted infection, all of which are listed as "special precaution cases requiring a highly skilled surgeon and facilities" by the World Health Organisation (WHO, 1996). In addition, some 5 percent reported white discharge (possibly indicative of reproductive tract infection) and irregular periods. While none of these pre-existing conditions a priori argue against sterilisation, they do warrant proper screening and possible treatment, and certainly call for sharing of information with the client about possible implications and alternative methods that would be more appropriate given the client's medical history. 


\section{Table 1:}

Profile of sterilisation clients $(\mathrm{N}=246)$

\begin{tabular}{|c|c|}
\hline Characteristic & \\
\hline $\begin{array}{l}\text { Current age } \\
\text { Mean } \\
\text { Median } \\
\% \text { aged }<21\end{array}$ & $\begin{array}{r}26.1 \\
25.0 \\
8.9\end{array}$ \\
\hline $\begin{array}{l}\text { Marital status } \\
\% \text { currently married }\end{array}$ & 98.8 \\
\hline $\begin{array}{l}\text { Religion (\%) } \\
\text { Hindu } \\
\text { Christian } \\
\text { Muslim }\end{array}$ & $\begin{array}{r}78.0 \\
12.7 \\
7.3\end{array}$ \\
\hline $\begin{array}{l}\text { Education } \\
\text { Mean years of schooling }\end{array}$ & 8.0 \\
\hline $\begin{array}{l}\text { Family size } \\
\text { Mean no. of surviving children } \\
\text { Mean no. of surviving sons } \\
\text { Mean no. of surviving daughters } \\
\% \text { who experienced any infant/child mortality }\end{array}$ & $\begin{array}{l}2.2 \\
1.2 \\
1.0 \\
4.0\end{array}$ \\
\hline $\begin{array}{l}\text { Family type }(\mathbf{0}) \\
\text { Nuclear } \\
\text { Non-nuclear }\end{array}$ & $\begin{array}{l}67.1 \\
32.9\end{array}$ \\
\hline $\begin{array}{l}\text { Current residence }(\mathbf{\%}) \\
\text { Chennai city } \\
\text { Small town } \\
\text { Rural }\end{array}$ & $\begin{array}{l}69.5 \\
13.2 \\
16.3\end{array}$ \\
\hline $\begin{array}{l}\text { Home ownership and type } \\
\% \text { who own their homes } \\
\% \text { residing in concrete structures }\end{array}$ & $\begin{array}{l}50.8 \\
54.9\end{array}$ \\
\hline $\begin{array}{l}\text { Occupation* }(\mathbf{\%}) \\
\text { Housewife } \\
\text { Production \& related work, transport, labourers } \\
\text { Service } \\
\text { Professional/technical/administrative, executive and managerial } \\
\text { Clerical and sales } \\
\text { Agriculture and allied }\end{array}$ & $\begin{array}{r}81.3 \\
6.5 \\
3.3 \\
3.6 \\
2.4 \\
2.0\end{array}$ \\
\hline $\begin{array}{l}\text { Type of sterilisation procedure (\%) } \\
\text { Post-partum tubectomy } \\
\text { Interval trans-abdominal } \\
\text { Interval laparoscopy }\end{array}$ & $\begin{array}{r}89.4 \\
7.3 \\
3.3\end{array}$ \\
\hline
\end{tabular}

*excludes 2 clients for whom occupation was not classified or missing.

11 Informed Consent in Sterilisation Services 


\section{Quality of "informed" consent}

\section{Provision of information}

The MOHFW guidelines state that a sterilisation client should be informed about all available contraceptive alternatives prior to the adoption of sterilisation. However, as Table 2 indicates, pre-sterilisation awareness of contraceptive options other than sterilisation was somewhat limited among respondents. While most clients (about 90\%) were aware of IUDs, somewhat fewer (almost 80\%) were aware of condoms and some two-thirds were aware of male sterilisation and oral contraceptives. Far fewer were aware of other nonterminal methods such as injectables or emergency contraception, or such traditional methods as withdrawal and the rhythm method. With regard to the prior use of nonterminal contraceptive methods, only 35 percent reported the use of any other method the largest group were those who had used IUDs prior to sterilisation (30\%) (not shown in tabular form).

\section{Table 2:}

Clients' awareness of specific contraceptive methods prior to sterilisation ( $N=246)$

\begin{tabular}{|c|c|c|c|}
\hline \multirow[t]{2}{*}{ Method } & \multicolumn{3}{|c|}{$\begin{array}{l}\% \text { reporting awareness of contraceptive } \\
\text { methods other than sterilisation* }\end{array}$} \\
\hline & $\begin{array}{l}\text { Spontaneous } \\
\text { reporting }\end{array}$ & $\begin{array}{l}\text { Reporting } \\
\text { on probing }\end{array}$ & Total \\
\hline IUD & 65.4 & 24.0 & 89.4 \\
\hline Condoms & 42.3 & 37.4 & 79.7 \\
\hline Vasectomy & 6.9 & 59.8 & 66.7 \\
\hline Oral contraceptives & 29.7 & 34.1 & 63.8 \\
\hline Rhythm method & 4.1 & 19.5 & 23.6 \\
\hline Withdrawal & 2.0 & 10.6 & 12.6 \\
\hline Emergency contraception & 1.2 & 7.3 & 8.5 \\
\hline Injectables & 2.4 & 6.1 & 8.5 \\
\hline
\end{tabular}

* Multiple responses, percentages do not total 100.

Study findings show that in most cases, clients were not given comprehensive information on female sterilisation or other methods of contraception (Table 3). Only 20 percent of clients were given information on certain side-effects and asked to return to the provider if these were experienced. The information provided tended to be far from comprehensive, focusing on post-operative complications such as vomiting, headache, stomach pain, problems in sutures and bleeding; not a single woman reported that she had been informed of some of the complications associated with female sterilisation mentioned in the MOHFW guidelines. Information on matters aside from complications and side-effects was given to even fewer women. For example, specific information about the procedure to be adopted was given to only 5 percent of clients. Even fewer $(\mathrm{N}=6 ; 2.4 \%$ of all respondents) 
reported that they were given information on alternative contraceptive methods by health providers; even so, the information provided was not comprehensive and the methods covered did not go beyond vasectomy and IUDs. Although of concern to many respondents, information on failure rates associated with tubectomy was provided to no more than 1 percent of our sample.

\section{Table 3:}

Clients' reports of information given by health care providers prior to sterilisation $(\mathrm{N}=\mathbf{2 4 6})$

\begin{tabular}{l|c|}
\hline Client reporting following information provided: & $\%$ \\
\hline Certain side-effects of sterilisation; clients asked to return & 20.3 \\
if these side-effects were experienced* & 4.9 \\
Details of the sterilisation procedure to be adopted & 2.4 \\
Alternative contraceptive methods & 1.2 \\
Potential failure rates of sterilisation & 1.2 \\
Immediate complications following sterilisation** & \\
* These include pain, bleeding and problems in sutures. & \\
**These include vomiting, headache and stomach pain.
\end{tabular}

Women perceived that information tended to be provided in a way that was biased towards convincing the client to undergo sterilisation. For example, two clients who underwent sterilisation following a caesarean section delivery reported that the provider had not discussed with them the option of interval sterilisation, the merits and demerits of laparoscopic sterilisation and vasectomy, nor raised concerns about the implications of infant death or the prospects for re-canalisation.

When it was decided that the delivery would be a caesarean, she [health provider] asked, "Will you have it [sterilisation] alongside?" Why come again for this [sterilisation]? If the delivery had been normal I wouldn't have done it [sterilisation]. I would have gone home for some time, taken rest, and then done it. (27 years, B.Com, 1 son, 1 daughter)

The doctor said, "If you are interested [in sterilisation], go abead. Anyway we are going to open your abdomen." He [my husband] was against it. He felt he would not be able to share my pain, that he should do something, but anyway it was a caesarean and they were going to open my abdomen in any case. Otherwise he would have gone for vasectomy. (30 years, M.Phil, 1 son, 1 daughter)

\section{Client satisfaction with quality of information provided}

Findings reiterate client dissatisfaction with the quality of information received from health care providers. Indeed, more than half of all respondents reported that they were not completely satisfied with the information provided to them in the health care setting (Table 4). A similar proportion (about 53\%) also felt that providers should discuss alternatives to sterilisation as well as the advantages and disadvantages of sterilisation visà-vis other methods of contraception. When probed the majority of respondents agreed 
that they would have liked to have received more information, in particular on follow-up care $(24.1 \%)$, the sterilisation procedure $(12.4 \%)$ and its side-effects $(5.1 \%)$ (not shown in tabular form).

\section{Table 4:}

Client satisfaction with information provided $(\mathrm{N}=246)$

\begin{tabular}{l|c}
\hline Client reporting: & $\%$ \\
\hline \begin{tabular}{l|} 
Completely satisfied with information given by provider \\
Providers should discuss alternatives to sterilisation
\end{tabular} & 44.3 \\
Providers should discuss the merits of sterilisation vis-à-vis & 54.1 \\
alternative methods & 52.8 \\
Providers should discuss the disadvantages of sterilisation \\
vis-à-vis alternative methods
\end{tabular}

It is interesting to note that 44 percent of women clients reported that they were satisfied with the information given by the health care provider, reflecting the low expectations of clients and their lack of awareness of their right to information on contraceptive services. For example, as a young non-literate client with two sons reported: "What the doctor says is for our good. The doctor is like God. They are there to save us. They will only do good for us." Similar findings are observed in other studies of client attitudes to informed consent, reflecting the implicit trust held by the community in the medical system, low expectations of services and a lack of understanding of what is a client's right (Decosta et al., 2004).

In-depth interviews suggest that fears about sterilisation failure remain an obvious concern among women, even following the procedure. For example, one woman, whose earlier sterilisation had failed, reported that she was informed about failure rates only at the time of the second sterilisation. As the following narrative suggests, the information provided appears more to absolve the provider of the responsibility of adverse outcomes than to fully inform the client, and the use of the oral contraceptives provided was so poorly explained that the respondent suspected that it was provided to protect her from yet another failed sterilisation:

I: What did they say?

R: Failed sterilisation can accidentally happen to anybody. We can't do anything. Earlier it was possible to start a legal case for failed sterilisation but now you can't do anything. It seems that they [providers] have put something like that in a letter... [to say] that it is not their fault [if the procedure fails].

I: Do you still feel scared?

$14 \mid$ Rajalakshmi 
R: Yes, it [fear] is there... because... we don't know how they have done it [the sterilisation].

Because they themselves think there are chances [of failure], that is why they gave me tablets for three months, saying, "Have them and see". (29 years, educated up to Class 5, 2 daughters)

Several respondents who expressed their fear of having a failed sterilisation even sought clarifications from researchers about the likelihood of method failure. For example:

My neighbour had a laparoscopy operation [sterilisation] and had a baby. My mother too, after the operation, after a year, got pregnant and my brother was born. [Pauses and asks the investigator] Will it happen like that?... I am scared. I won't ask them [hospital staff]. (18 years, educated up to Class 11, 2 sons)

In a society in which the provider-client relationship is hierarchical, women would feel comfortable expressing their concerns to providers only if providers are open and invite questions from their clients. Findings however suggest that while women had a number of concerns, they rarely expressed these concerns to their providers. For example, while 60 percent of women reported one or more concerns, only 43 percent discussed these with a provider (not shown in tabular form). Our findings also indicate that only 62 respondents $(25 \%)$ were invited by the doctor to discuss their concerns, and 50 of these respondents (81\% of those invited) actually discussed their concerns with the provider (not shown in tabular form), suggesting the central role played by the provider in encouraging clients to be fully informed.

In their narratives, many women, even better-educated clients seeking private facilities, expressed reluctance to raise questions with health care providers because they felt shy, perceived that the provider lacked the time to explain, or feared that questions would be misinterpreted as lack of trust:

I don't know why but I am usually scared to ask the doctor any questions. So I don't ask. I listen carefully to whatever they say. (31 years, educated up to Class 10, 2 daughters)

Maybe the doctor should take the responsibility to explain about the procedure, how they do it. Anyway I trust the doctor. (34 years, postgraduate, 2 daughters)

Also underlying women's hesitation to express their concerns to the provider were previous negative experiences with providers with regard to other methods of contraception. In in-depth interviews, women noted that providers were selective in the information they chose to provide, typically focusing only on the method that they perceived as appropriate for the woman. For example, a client reported that the provider had initially promoted an IUD as an appropriate method for her and when she resisted, focused only on injectables. When women returned to their providers with methodrelated complaints, they reported that interactions were unsatisfactory and that providers tended to discount their experiences as "normal". 
In short, study findings clearly highlight that women were not fully informed about female sterilisation, options to sterilisation, the process or potential failure rates, both before and after the decision to undergo sterilisation was made. The above discussion indicates moreover that although women reported a number of concerns, they were inhibited from actively seeking clarification of these concerns from their providers. In many cases, inhibitions stemmed from the limited rapport women had with their providers and from the hierarchical nature of provider-client relations that reinforce the perception that the doctor knows best. Given that sterilisation is a terminal method of contraception and is based on voluntary choice, the finding that decision-making may not have been based on complete information is disturbing. Findings also suggest that women are themselves dissatisfied with the information given by providers, and that they expect doctors to be proactive in addressing their concerns before and after undergoing sterilisation. 


\section{Quality of documentation of consent}

In order to better understand the consent-taking process, the consent forms used in the study settings were collected and analysed. In addition, respondents were asked to recall the content of the consent form that they had signed. Findings suggest that aside from the two public hospitals, there was no standard consent form for sterilisation. Of the 16 hospital forms collected, 11 forms were generic and used for any kind of surgery. Twelve were written only in Tamil (the local language) or English (6 each) and only four were in both languages.

\section{Table 5:}

Content of consent forms used in participating facilities ( $N=16)$

\begin{tabular}{l|c} 
Consent form contained the following information: & No. of forms \\
The client's signature on the form is mandatory & 16 \\
Anaesthesia will be used & 14 \\
The doctor's signature on the form is mandatory & 9 \\
The client has voluntarily agreed to undergo sterilisation & 7 \\
There are alternative methods to female sterilisation & 7 \\
There are chances of failure in female sterilisation & 7 \\
The client has read the form/had the form read out to her & 6 \\
The client will not hold the doctor/hospital responsible for & 6 \\
any adverse outcomes & 5 \\
There could be complications following sterilisation & 2 \\
Sterilisation is permanent and renders the woman infertile & 2 \\
The client has the right to withdraw consent & 2 \\
The husband's signature is needed & 2 \\
Declaration of the doctor that he/she has explained the procedure &
\end{tabular}

Note: 16 consent forms were considered because two public and two private facilities had the same form.

Most consent forms did not include details of the type of sterilisation procedure to be undertaken, the doctor's responsibilities or the client's rights. As can be seen from Table 5, even the most important aspect of sterilisation - that it is an irreversible procedure - was mentioned in only one-third of all forms. Information on alternative methods of contraception, method failure and complications following sterilisation was included in fewer than half of all forms. A blanket declaration that the client would not hold the doctor or hospital liable for any adverse outcomes was included in six forms.

By and large, women did not identify these as consent forms; rather they referred to them as "incentive" forms that they signed before receiving payment. ${ }^{3}$ In fact, clients reported

3 In public hospitals, Rs. 200 is paid as compensation to every woman who accepts sterilisation.

17 Informed Consent in Sterilisation Services 
having signed on the case record sheet itself where the doctor/nurse wrote at the bottom of the page: "I consent to the family planning operation with anaesthesia".

\section{Table 6:}

Documentation of consent and women's recall of the content of the consent form $(\mathrm{N}=246)$

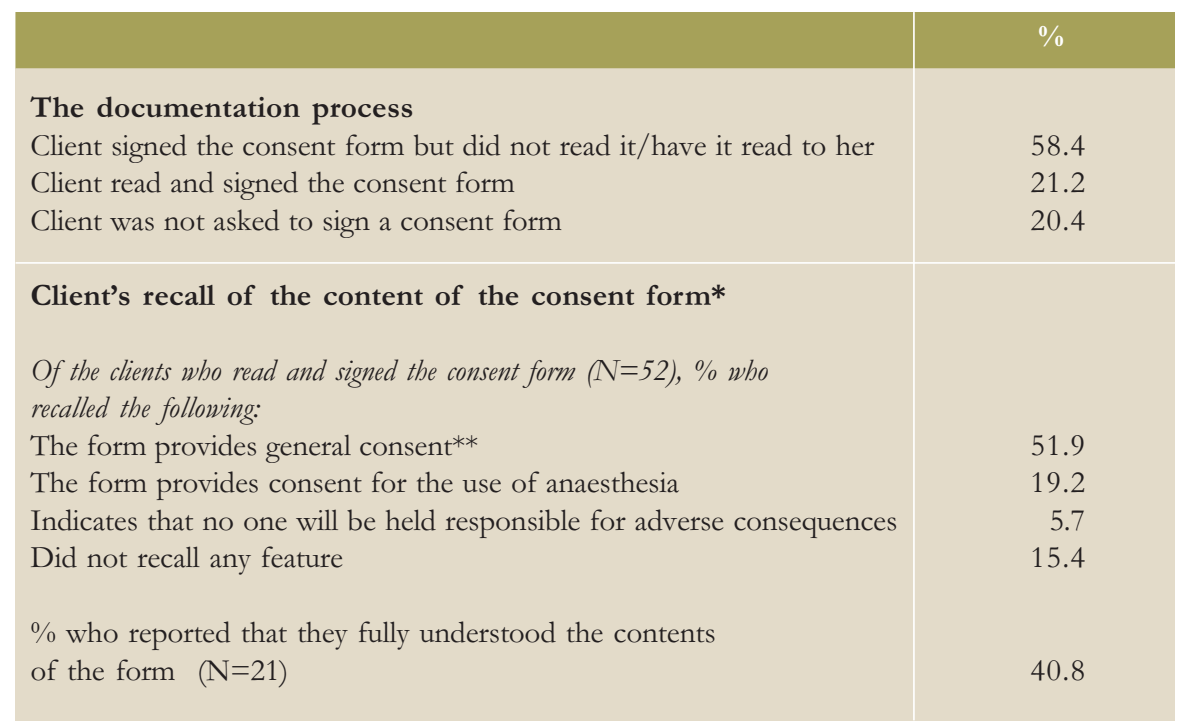

*Multiple responses, percentages do not total 100.

** Only general statements such as "I agree/accept/consent/ am willing to undergo sterilisation" were recalled.

While women are required to give written authorisation by providing a signature on the consent form, it is unclear whether the information provided in the form was in fact read by clients (or in the case of uneducated clients, whether the form was read out to them) or whether clients properly understood its content. As seen in Table 6, few clients $(21.2 \%)$ reported that they had read and signed the consent form. Indeed, one in five women reported that she had not been asked to sign a consent form. In addition, almost three in five reported that while they were asked to sign the form, they were not given an opportunity to read the form or have it read to them.

Although women were interviewed just before being discharged from the facility following the sterilisation procedure, their recall of the content of the consent form was extremely limited. Indeed, only a few women who reported having read and signed the form $(\mathrm{N}=52)$ could recall any details (see Table 6). About half of these women said that the form contained general statements such as "I accept", "I agree", and "I am willing" to undergo sterilisation. Of the others, several recalled only specific items in the consent form: for example, about 20 percent mentioned that they had been asked to agree to the use of anaesthesia and a few $(\mathrm{N}=3)$ said that they had agreed not to hold the provider responsible for adverse consequences. Several women for whom sterilisation had been conducted in 
conjunction with a second procedure (for example, a caesarean section delivery or an induced abortion) were confused about the main features of each form. Finally, eight of the 52 women who reported that they had read the form could not recall even a single item in the form.

Women were asked to specifically recall information in the $f$ on the rights of clients and the respnsibilities of providers. Only six (11\% of those who read the form) recalled, when probed, that some information on the rights of clients had been included in the form and only three $(6 \%)$ recalled any information on the responsibilities of the provider (not shown in tabular form). Clearly, although consent forms were administered to the majority of respondents, not a single respondent could recall the content in a comprehensive way.

Clients who reported having signed a consent form $(\mathrm{N}=196)$ were further probed about the consent-taking process (see Table 7). Of these respondents, 10 percent reported that they were simply handed the form and asked to sign it without reading it; 35 percent reported that they were given the form less than 10 minutes before the actual procedure; and only half reported that it was a doctor who obtained their signature. Moreover, fewer than one in three reported that there was time to absorb the content of the form and only 5 percent reported that there was any opportunity to discuss its contents with the provider in the course of the consent-taking process. Some 30 percent reported that they were not informed about the purpose of signing the consent form.

\section{Table 7:}

Among clients who signed the consent form, women reporting experiences of the consent-taking process $(\mathrm{N}=196)$

\begin{tabular}{l|c} 
Client reporting that: & $\%$ \\
\hline Someone other than a doctor took the client's signature & 50.0 \\
The form was given to the client less than 10 minutes before sterilisation & 35.0 \\
There was time to read and absorb the contents of the form & 30.0 \\
No one explained the purpose of the signature to the client & 28.0 \\
The client signed the form without reading it & 9.8 \\
Some discussion took place at the time the form was signed & 5.0
\end{tabular}

While MOHFW guidelines specify that consent for sterilisation should not be obtained if the client is under physical or mental stress (MOHFW, 1999), at least two women reported that they were in labour (caesarean section deliveries) or recuperating from delivery when they were asked to sign the forms; these women reported that the content of the consent form was irrelevant as they had already made the decision to undergo sterilisation. As one client who underwent a second sterilisation after seven years following failure reported:

They [the providers] did not say anything about why I was required to sign this [form]...they just told me to put my signature ... in that pain, I didn't know what to do, so I signed the form. (29 years, educated up to Class 5, 2 daughters) 
In their narratives, clients also reported that the documentation process was hurried. Several clients noted that they were not given the form to read, much less to reflect upon its contents. Consequently, misperceptions about the documentation process prevailed, for example, that hospital rules prohibit providers from giving the consent form to clients, as described in the following narrative:

No one explained [the consent form] to me. They take the signatures in a burry. At that time they ask, "Do you agree?" If they hand the form to us to fill it up, then we would have a chance to read the form. We could read what is in the form and sign it. We would come to know the various advantages and disadvantages [of the procedure]. We would also know whether we are being compelled or not. But according to hospital rules, they cannot give the form to you in your hand. (31 years, educated up to Class 10, 2 daughters)

Thus far, our findings have suggested that by and large, women were not fully informed about sterilisation or alternative contraceptive methods, nor did the consent-taking process truly enable them to understand the information provided, give informed consent or make an informed choice.

\section{Table 8:}

Clients' perceptions of the value of the consent process $(\mathrm{N}=246)$

\begin{tabular}{l|r|}
\hline Client reporting:* & $\%$ \\
\hline The consent form is necessary & 71.0 \\
\hline The consent form benefits: & 84.0 \\
Doctor & 82.0 \\
Hospital & 72.0 \\
Client & 49.0 \\
Client's husband & \\
\hline Main advantage of the consent-taking process & \\
& 40.0 \\
Physician and facility related: & 27.0 \\
Protects the doctor in case of adverse consequences & 12.0 \\
Protects the hospital in case of adverse consequences & 14.0 \\
Ensures that the doctor follows the rules of the hospital & 5.0 \\
Documents that hospital authorities have followed the rules & \\
Certifies providers' efforts to acheive sterilisation targets & 22.0 \\
& 10.0 \\
Client related: & 3.7 \\
Provides documentary proof that the client has undergone surgery & 8.0 \\
Helps the client avoid problems in future & \\
Confirms the client's consent & 10.0 \\
Indicates the client's acceptance of small family norm & \\
Spouse related: & \\
Ensures that the husband has been informed &
\end{tabular}

*Multiple responses, percentages do not total 100. 
It is interesting to note that the benefits of the consent-taking process were perceived by clients as a form of protection for the health provider and the facility, and as proof of the client having undergone sterilisation (Table 8). Also interesting is that the form was viewed as a form of protection for the woman herself, that is, to prevent family quarrels arising from possible allegations that the woman did not inform key family members. A few women $(8 \%)$ suggested that the signature on the consent form implied the client's acceptance of the small family norm or certified efforts by providers to achieve sterilisation targets $(5 \%)$. Women also reported $(10 \%)$ that the consent-taking process provides proof that the husband has been informed about his wife undergoing sterilisation. A substantial number of women (about 25\%) reported that they did not know what the signature implied and had never thought about its significance. A few women noted in interviews the inadequacy of the consent form in making providers and facilities accountable for complications or failure, for example:

The doctors say that they are not responsible but they need to be accountable. If the situation is uncertain or the woman has some problem, then they should mention all these things [in the consent form]. But in normal circumstances, telling like this [that they cannot take responsibility] is wrong. (30 years, M Phil, 1 son, 1 daughter)

If there is any problem, the doctor is not held responsible... as he will say that I have signed [the form], that I have consented....Patients have to face their problems alone. We cannot ask the doctor any questions... if there is a danger to life, the doctor will ask us indirectly to accept that [death] also. (31 years, educated up to Class 10, 2 daughters)

In short, the process of consent-taking was perceived by many women as a formality, offering clients little opportunity to absorb the contents of the form. In most cases, minimal efforts were made to explain the consent form to those who could not read it, or found it difficult to understand its contents. In no case did the process provide opportunities for women to gather additional information or to evaluate their decisions. Finally, clients themselves did not perceive that the process offered them an opportunity to make a fully informed choice; rather, they perceived the process as one intended to protect the provider and facility from malpractice, and offer no more than written proof of sterilisation for the woman. 


\section{Quality of "voluntary" consent}

Findings suggest that women do not necessarily make a free and voluntary decision and that they are not always, in practice, the final decision makers. Providers played a key role in the final decision to adopt sterilisation. While about one in five women reported that they themselves had indeed made the final decision (Table 9), a similar number reported that providers prompted them to make the final choice (not shown in tabular form). It is not uncommon or unacceptable for providers to advise and motivate women to adopt sterilisation, but the lines between motivation and compulsion tend to become blurred in reports of client-provider interaction. Indeed, 9 percent of respondents reported that they were pressured/compelled by the provider into accepting the sterilisation (see Table 9).

Several women reported in interviews that providers scolded or shouted at women clients, that they created undue fear of the adverse health consequences of further pregnancies or alluded to denial of further care, non-issue of birth certificates for newborns or discharge summaries and so on if they did not accept sterilisation. Subtle and not so subtle pressure to adopt sterilisation was reported:

They [providers] should talk politely to the patient. They told me, "You are anaemic, yet you want to have two children." So, does this mean that I have to ask their permission to have children? (25 years, educated up to Class 10, 1 son, 1 daughter)

They [providers] compel patients to undergo sterilisation. They should not compel them because it is our problem so we should decide whether or not to do so. (31 years, educated up to Class 10, 2 daughters)

The doctor wants to have numbers [meet a target] so they convince us by telling us about the problems that we will have by having more children. (28 years, educated up to Class 8,2 sons)

Several narratives suggest the hierarchical nature of provider-client relations and the extent to which women were influenced by the providers' counsel, even when poor quality of interaction with providers was experienced:

I felt bad when they scolded me but what they say is only for our good. They say it [another pregnancy] will affect our health. Now I feel they are not at fault. (27 years, educated up to Class 5, 2 daughters)

$22 \mid$ Rajalakshmi 
Even where women apparently expressed "consent," the extent to which the consent reflects a well thought out decision remains unclear, as the following narratives suggest:

I was alone in Ward 6 two days after my delivery. My mother was not there. I had not decided to undergo sterilisation. They [the doctor] called me suddenly and asked, "Will you agree to undergo sterilisation?" I said no and went away. In the morning I told my mother that I had not agreed, and I asked her what I should do. My mother said,- "Why did you say no? Go and tell them you agree to do family planning." (18 years, educated up to Class 11, 2 sons)

\section{Table 9:}

The consent-taking process: Clients' experiences and perceptions ( $\mathrm{N}=246)$

\begin{tabular}{|c|c|}
\hline Client reporting:* & $\%$ \\
\hline $\begin{array}{l}\text { Decision-making on sterilisation } \\
\text { Decision made by: } \\
\text { Client alone } \\
\text { Client and spouse jointly } \\
\text { Spouse alone } \\
\text { Mother-in-law } \\
\text { Mother } \\
\text { Health care provider } \\
\text { Others }\end{array}$ & $\begin{array}{r}22.7 \\
58.8 \\
9.3 \\
7.3 \\
6.1 \\
2.8 \\
4.1\end{array}$ \\
\hline $\begin{array}{l}\text { Experience of compulsion } \\
\text { Client faced compulsion, threats and intimidation from provider when } \\
\text { making a choice }\end{array}$ & 9.0 \\
\hline $\begin{array}{l}\text { Third-party authorisation for sterilisation } \\
\text { Clients reporting a second signature was taken on the consent form } \\
\text { Of those }(N=180) \text { reporting a second signature was taken, signature } \\
\text { taken was that of: } \\
\text { Husband } \\
\text { Mother } \\
\text { Mother-in-law } \\
\text { Sister } \\
\text { Others }\end{array}$ & $\begin{array}{r}56.1 \\
27.2 \\
9.4 \\
4.1 \\
3.7\end{array}$ \\
\hline $\begin{array}{l}\text { Perceptions of who should take the final decision on sterilisation } \\
\text { Woman and husband } \\
\text { Woman alone } \\
\text { Husband, provider, elders } \\
\text { Don't know }\end{array}$ & $\begin{array}{r}68.0 \\
15.0 \\
11.0 \\
5.0\end{array}$ \\
\hline $\begin{array}{l}\text { Perceptions of whose signature is most important on the consent form } \\
\text { Client } \\
\text { Husband } \\
\text { Mother } \\
\text { Accompanying person } \\
\text { Others }\end{array}$ & $\begin{array}{r}37.4 \\
72.8 \\
9.0 \\
6.1 \\
2.0\end{array}$ \\
\hline
\end{tabular}

23 Informed Consent in Sterilisation Services 
Contrary to Government of India guidelines, clients reported that providers required a second signature on the consent form (Table 9). Some 44 percent of clients reported the presence of a spouse or family member when they signed the consent form, and privacy in general was rated as adequate by no more than 70 percent of clients (not shown in tabular form). Moreover, as seen in Table 9, almost three-quarters of all clients reported that their signature was not considered sufficient but that a second signature was also taken on their consent forms, generally that of the husband, mother or mother-in-law. In some cases, a family member signed the form without informing the client, as seen in the following quote:

My mother-in-law signed the form without my knowledge. (25 years, post-graduate, 2 sons, 1 daughter)

Women themselves did not recognise their right to self-determination in the final decision on sterilisation. Clients often reiterated that the husband or other family members must be involved in the final decision (see Table 9). Most women also held the view that the consent form should contain the signatures of both the woman and her husband. The extent to which this perception reflects a recognition of male dominance or a mechanism to involve men in joint decisions regarding family planning is unclear.

In-depth interviews reiterate that providers themselves expect that the husband's consent has been taken for sterilisation, even when they do not actually demand his signature:

They [the providers] asked, "Is your husband here? Are you putting [your signature] only after getting his consent? Because there is a rule that you should sign only after you get his consent." (29 years, educated up to Class 7, 2 sons)

In short, while the majority of women did indeed report a sense of relief following sterilisation, knowing that they would be avoiding unwanted pregnancies in future, the extent to which they made the final decision themselves, and the extent to which the decision was fully informed, freely made and followed proper consent-taking procedures, is less clear. 


\section{Conclusion and recommendations}

At the outset we defined informed consent as an ongoing process involving several players, that enables clients to arrive at an informed, understood and voluntary decision, largely based on interaction between the client and the provider. Our findings underscore that although all the women respondents did wish to practise a method of contraception, and did want to adopt sterilisation, several limitations were noted in the process of providing informed consent.

First, inadequate information was provided to women to enable them to weigh their options and arrive at the decision to accept sterilisation in an informed way. Even when an apparent decision was taken to "accept" sterilisation, the client was not given a detailed explanation about the surgery, its risks and consequences.

Second, the process of documentation of consent was poorly conducted in the study setting. The consent forms in most hospitals were designed to protect providers and institutions rather than the clients. There was no uniformity across hospitals in terms of the content of the form or the procedure for administering the form. Some forms did not even contain the most essential information about sterilisation, namely that it is a terminal method. Most women reported that the process of obtaining a signature was conducted in a hurried manner, offering women little opportunity to absorb the content of the form. At times, signatures were taken when the woman was not competent to consent. The documentation process also violated the principle of autonomy, where the woman herself was often bypassed and consent was taken from her husband or other family members. A disturbing finding regarding the decision-making process is the subtle and sometimes direct role of health care providers in influencing the decision to accept sterilisation.

Third, the nature of client-provider interaction observed in the study suggests that the environment was not conducive to ensuring the exercise of women's right to informed consent. In many cases, there was no discussion between the client and provider about sterilisation. Although many women had concerns before adopting the method, only a few raised them with their providers. Hierarchical provider-client relations persist and women tend to rely on the doctor as the best judge. Clients were unaware of their rights and the duties of providers. Indeed, clients perceived the documentation of consent as one intended to protect the provider and facility from malpractice, which simply offered the woman written proof of having undergone sterilisation.

Findings underscore the need for interventions at different levels- that of women in general and as family planning clients, health care providers, family planning institutions and at the policy level. There is a need to sensitise women to the fact that as clients they have the right to seek information from providers, the right to decide of their free will whether or not to accept sterilisation and the right to exercise informed dissent. There is also a need to equip women with comprehensive information before they enter a health care institution so that they can make an informed choice on the method to be adopted. 
At the level of providers and facilities, our findings suggest the need for greater provider acknowledgement of clients' rights, of the need to provide quality care that is sensitive to women's apprehensions and reluctance to make demands on providers and to respect the right of women to exercise their own choice. More specifically, there is a need to apprise, sensitise and train all levels of health care providers involved in reproductive health services about the need for informed consent and to make providers and facilities accountable for ensuring understood consent among women undergoing sterilisation. Training of providers on communication and counselling skills would improve the informed consent process. Finally, there is a need to popularise informed consent as a desirable and achievable goal in the reproductive health programme and to demonstrate a stronger policy level commitment to the need for informed consent. 


\section{References}

American College of Obstetrics and Gynaecology. 2004. Ethics in obstetrics and gynaecology, available at<http://www.acog.org/from_home/publications / ethics $/$ ethics 009 .pdf\#search $=\% 22 \mathrm{Acog} \% 20$ informed $\% 20$ consent $\% 22>$ accessed on 12 September 2006.

Chaudhuri, S.K. 2004. Practice of Fertility Control. $6^{\text {th }} \mathrm{ed}$. New Delhi: Elsevier.

Cook, R.J., B.M. Dickens and M.F. Fathalla. 2003. Reproductive Health and Human Rights. Oxford: Clarendon Press.

Decosta, A., N. D’Souza, S. Krishnan et al. 2004. "Community-based trails and informed consent in rural north India," Journal of Medical Ethics 30: 318-323.

Duggal, R., and S. Barge. 2004. Abortion Services in India: Report of a Multi Centric Enquiry. Mumbai: CEHAT/HealthWatch.

Gupte, M., S. Bandewar and H. Pisal. 1999. “Women's perspectives on the quality of general and reproductive health care: Evidence from rural Maharashtra," in Improving Quality of Care in India's Family Welfare Programme, ed. M.A. Koenig and M.E. Khan. New York: Population Council, pp. 117-139.

Indian Council of Medical Research (ICMR). 2000. Ethical guidelines for biomedical research on human subjects, New Delhi, available at <http:/ /www.icmr.nic.in/ ethical.pdf > accessed on 2 September 2006.

International Institute of Population Sciences (IIPS) and ORC Macro. 2000. National Family Health Survey (NFHS-2), 1998-1999: India. Mumbai: IIPS.

International Institute for Population Sciences (IIPS) and Johns Hopkins University. 2005. Follow-up Study of NFHS-2 Respondents in Four Indian States: Final Report.

Mumbai: IIPS.

Khan, M.E., R.B. Gupta and B.C. Patel. 1999. "The quality and coverage of family planning services in Uttar Pradesh: Client perspectives," in Improving Quality of Care in India's Family Welfare Programme, ed. M.A. Koenig and M.E. Khan. New York: Population Council, pp. 44-69.

Kim, Y.M., A. Kols and S. Mucheke. 1998. "Informed choice and decision making in family planning counselling in Kenya," International Family Planning Perspectives 30(1): 4-11 \& 42 . 
Koenig, M.A. and M E. Khan. 1999. "Introduction," in Improving Quality of Care in India's Family Welfare Programme, ed. M.A. Koenig and M.E. Khan. New York: Population Council, pp.1-16.

Kumar, R. 2006. "Balancing population concerns with women's rights," available at $<$ http://www.cceia.org/resources/publications/dialogue/2_06/online_exclusive/ 652.html> accessed on 10 June 2007.

Mayfield, M., J.A.C. Perez and E. Landry. n.d. "Study on informed consent for sterilisation: Mexico," unpublished.

Ministry of Health and Family Welfare (MOHFW). 1999. Standards for Female and Male Sterilisation. New Delhi: Government of India.

Muraleedharan, V.R. 1999. "Characteristics and structure of private hospital sector in urban India: A study of Madras city," in Private Health Sector in India: Review and Annotated Bibliography. Mumbai: CEHAT, Chennai: IIT, New Delhi: JNU.

Murthy, N. 1999. "The quality of family welfare services in rural Maharashtra: Insights from a client survey," in Improving Quality of Care in India's Family Welfare Programme, ed. M.A. Koenig and M.E. Khan. New York: Population Council, pp. 33-48.

National Bioethics Advisory Commission. 2001. "Chapter three: Voluntary informed consent," in Ethical and Policy Issues in International Research: Clinical Trials in Developing Countries, Vol. 1: April, pp. 35-53, available at <http://bioethics.georgetown.edu/ $\mathrm{nbac} /$ pubs.html> accessed on 21 May 2006.

Preziosi, M.P., A. Yam, M. Ndiaye et al. 1997. "Practical experiences in obtaining informed consent for a vaccine trial in rural Africa," New England Journal of Medicine 336(5):1-5.

Ravindran, T.K.S. 1999. "Rural women's experiences with family welfare services in Tamil Nadu," in Improving Quality of Care in India's Family Welfare Programme, ed. M.A. Koenig and M.E. Khan. New York: Population Council, pp. 70-91.

Registrar General, India (RGI). 2005. "Fertility tables," available at <http:// www.censusindia.net/results/fseries_tables/f_series_tables_2001.htm $>$ accessed on 6 September 2006.

Registrar General, India (RGI). 2006. "Maternal mortality in India: Trends, causes and risk factors, 1997-2003," available at <http:/ /www.censusindia.net/ Maternal_Mortality_in_India_1997-2003.doc> accessed on 6 September 2006. 
Roy, T.K. and R.K. Verma. 1999. “Women's perceptions of the quality of family welfare services in four Indian states," in Improving Quality of Care in India's Family Welfare Programme, ed. M.A. Koenig and M.E. Khan. New York: Population Council, pp. 19-32.

Sabala, Swatija and Meena. 2002. Sterilisation—A Closer Look. Mumbai: Initiatives Women In Development.

Sreevidya, S. and B.W.C. Sathiyasekaran. 2003. "High caesarean rates in Madras (India): A population-based cross sectional study," British Journal of Obstetrics and Gynaecology 110(2): 106-111.

Tamil Nadu Government website. Available at < http://www.tn.gov.in/deptst/ EcoIndAllStates.htm> accessed on 7 February 2006.

Tamil Nadu Government, Directorate of Family Welfare website. "Statistical handbook," available at < http://www.tnhealth.org/dfwstat.htm> accessed on 7 February 2006.

United Nations (UN). 1994. Report of the International Conference on Population and Development. Cairo, 5-13 September.

Van Hollen, C. 2003. Birth on the Threshold. New Delhi: Zubaan.

Verma, R.K. and T.K. Roy. 1999. "Assessing the quality of family planning service providers in four Indian states," in Improving Quality of Care in India's Family Welfare Programme, ed. M.A. Koenig and M.E. Khan. New York: Population Council, pp. 169-182.

Visaria, L. 2000. "From contraceptive targets to informed choice," in "Women's Reproductive Health in India, ed. R. Ramasubban and S.J. Jejeebhoy. New Delhi: Rawat Publications, pp. 331-417.

World Health Organisation (WHO). 1996. Medical Eligibility Criteria for Contraceptive Use. WHOFRH/FPP/96.9.Geneva: WHO.

World Medical Association (WMA). 2000. "Declaration of Helsinki: Recommendations guiding physicians in biomedical research involving human subjects adopted in 1964 and last amended in 2000," available at <http://www.wma.net/e/policy/b3.htm> accessed on 6 September 2006. 


\section{Acknowledgements}

Several people provided valuable assistance during the course of this study. I am grateful to Bhuvaneswari and Sai Santhya for assistance in data collection and entry. I am also greatly indebted to all the women clients who gave their precious time for the interviews.

I would like to sincerely thank Shireen Jejeebhoy, K.G. Santhya, Shveta Kalyanwala and Komal Saxena at the Population Council for their guidance throughout the study and on previous versions of this report. I am grateful to Amar Jesani and Leela Visaria for reviewing the report; Deepika Ganju for editing the report; and Asha Matta for designing the report and overseeing production.

Finally, I would like to thank my family, without whose support this study would not have been possible. 
